\title{
ESTUDO DA FERMENTAÇÃO ALCOÓLICA E CARACTERIZAÇÃO FÍSICO-QUÍMICA DA PRODUÇÃO CASEIRA DE VINHOS DE UVAS DOS CULTIVARES RUBI
}

\author{
E. CALZETTA ${ }^{1}$, J. R. de MELO ${ }^{2}$ e R. G. MARQUES ${ }^{1}$ \\ ${ }^{1}$ Faculdade de Telêmaco Borba, Departamento de Engenharia Química \\ ${ }^{2}$ Universidade Estadual de Maringá, Departamento de Engenharia Química \\ E-mail para contato: nanacalzetta@hotmail.com
}

\begin{abstract}
RESUMO - O processo de fabricação de vinhos segue operações simples que consistem em: colheita, desengace, esmagamento, sulfitagem, fermentação e clarificação do vinho. O presente estudo tem por finalidade desenvolver um processo de produção caseiro de vinhos utilizando uvas dos cultivares Rubi e comparar a influência da adição de levedura na graduação alcoólica do fermentado. São apresentados e discutidos os resultados sobre o perfil de concentração de substrato e produto, como também os parâmetros fermentativos de rendimento, eficiência e produtividade na fermentação. $\mathrm{O}$ experimento realizado em batelada teve um tempo determinado de vinte dias apresentando todo o processo de fermentação alcoólica na presença e ausência de levedura Sacharomyces cerevisiae. Com base nos resultados obtidos verificou-se que os processos fermentativos, independente da adição ou não de levedura, apresentam resultados semelhantes, tanto na produção de etanol quanto na evolução da fermentação por meio de medidas dos parâmetros físicoquímicos e consumo de substrato. O teor de álcool final foi de $9,42^{\circ} \mathrm{GL}$ na amostra fermentada espontaneamente e $9,68^{\circ} \mathrm{GL}$ para a fermentação adicionada de levedura. A graduação alcoólica encontrou-se dentro do padrão exigido pela legislação brasileira, o que foi possível classificá-lo como vinho de mesa.
\end{abstract}

\section{INTRODUÇÃO}

A partir do século XX a produção do vinho expandiu-se no Brasil com o desenvolvimento da tecnologia na viticultura e estudos da enologia no desenvolvimento de leveduras selecionadas específicas para o processo de fermentação. Atualmente a cadeia produtiva do vinho é considerada a mais complexa do agronegócio e, embora sua produção seja simples, precisam ser levados em consideração os aspectos qualitativos, tais como as influências do ambiente e da tecnologia de produção, como também, de forma marcante, a uva usada como matéria-prima na elaboração do vinho (Wine, 2012).

A fermentação alcoólica é um fenômeno natural no qual os açúcares contidos nas uvas vão se transformar em álcool sob ação de micro-organismos e leveduras, tendo como resultado o mosto todo transformado em vinho, sendo um processo de desenvolvimento biológico com aplicação industrial e comercial (Tortora et al., 2005). A Sacharomyces cerevisiae é uma levedura muito utilizada durante o 


\section{9 a 22 de outubro de 2014 \\ Florianópolis/SC}

processo de fermentação porque ela é facultativa, ou seja, se desenvolve em condições aeróbicas ou aneróbicas com a presença de oxigênio ou na ausência deste (Tortora et al. 2005). Em condições industriais com maior importância econômica envolvendo os processos biotecnológicos, ela é utilizada pela capacidade de produzir e tolerar altas concentrações de etanol em meio ácido com elevado conteúdo de açúcares (Lima et al., 2001).

O vinho é uma bebida resultante da fermentação alcoólica do mosto de uvas, frescas, sãs e maduras, com um teor alcoólico de no mínimo 7\%, sendo tecnicamente somente chamadas de vinho, as bebidas fermentadas a partir de uvas, segundo processos tecnológicos admitidos por lei (Planalto, 1988). O processo de fabricação segue operações simples, tais como, a colheita, o preparo do mosto, a fermentação alcoólica, filtração, clarificação e conservação (Hashizume, 2001).

As categorias mais comercializadas no Brasil são os vinhos de mesa e os vinhos finos, que conforme o teor de açúcar pode ser: seco, ou seja, vinhos que não apresentam sabor doce e possuem de 0 a 5 gramas de açúcar por litro; semi-seco ou meio seco, vinhos nos quais já começamos a perceber o sabor doce, possuindo de 5,1 a 20 gramas de açúcar por litro; e o do tipo suave, vinho com sabor doce pronunciado, tendo concentrações superiores a 20,1 gramas de açúcar por litro (Henson, 2012). Os vinhos do tipo de mesa comum são elaborados em pequenas propriedades, como forma de agregação de valor, então, são produzidos por uvas de uma qualidade "inferior" tais como as de origem Vitis ruprestris, as quais são mais conhecidas como uvas viníferas ou americanas que dão ao vinho uma qualidade inferior. O cultivar Rubi, surgiu no município de Santa Maria no Estado do Paraná, como uma mutação somática da uva Itália, apresentando as mesmas características deste cultivar, mas com uma coloração rosada (Nachtigal e Camargo, 2005).

No presente trabalho foi desenvolvido um estudo sobre a fermentação alcoólica de uvas dos cultivares Rubi. Realizou-se um experimento laboratorial em batelada, efetuando-se a caracterização físico-química e análise da fermentação por meio de parâmetros fermentativos (produção de álcool, consumo de substrato, rendimento e eficiência do processo fermentativo).

\section{METODOLOGIA}

O processo de fermentação foi conduzido em batelada durante quatorze dias. À medida que a fermentação era conduzida, efetuaram-se algumas análises físico-químicas, tais como a medição de pH, temperatura, concentração de álcool, açúcar e turbidez. Os parâmetros fermentativos em relação à produtividade e eficiência do processo também foram analisados e serão apresentados. A seguir é descrita à metodologia de fabricação do vinho e a caracterização físico-química do fermentado.

\subsection{0 vinho caseiro}

Para a fabricação do vinho caseiro foi utilizado $4 \mathrm{~kg}$ de uvas Rubis, frescas, sãs e maduras. As frutas foram lavadas para eliminar resíduos ou insetos presentes nas bagas antes de serem processadas. $\mathrm{O}$ desengace das uvas foi realizado porque os ramos não podiam entrar em contato com o mosto, pois causariam sabor amargo e adstringente durante o processo de fermentação. A fermentação foi conduzida em batelada e o meio de cultivo deixado fermentar por 5 dias na presença 


\section{9 a 22 de outubro de 2014 \\ Florianópolis/SC}

de casca, a etapa subsequente foi realizar a primeira trasfega do mosto para o fermentador, retirandose as cascas. Foram adicionados $600 \mathrm{~g}$ de açúcar cristal ao mosto. Após chaptalização do mosto, foi adicionado $0,5 \mathrm{~g}$ de metabissulfito de sódio $\left(\mathrm{Na}_{2} \mathrm{~S}_{2} \mathrm{O}_{5}\right)$ para eliminar os micro-organismos indesejáveis, e deixar o mosto apropriado apenas para a proliferação de levedura utilizada na fermentação.

A fermentação na ausência de casca (segunda trasfega) foi conduzida em dois béqueres de 2L, constituindo-se de dois ensaios, um na presença de levedura e outro na sua ausência. Para efeito de estudo comparativo da eficiência do processo de fermentação alcoólica foi adicionado $20 \mathrm{~g}$ de levedura Saccharomyces cereviseae em um fermentador e o outro optou-se pela fermentação espontânea, ou seja, natural sem adição da levedura. Os recipientes foram vedados impedindo a entrada de ar no fermentador. Após fermentação total de quartoze dias, a terceira trasfega foi realizada para fazer a filtração do mosto fermentado, utilizando-se uma bomba a vácuo TECNAL, modelo TE058, papel filtro e funil de Buncher que foi encaixado no kitassato ligado a uma mangueira à bomba a vácuo. Na clarificação do vinho foi utilizada uma técnica caseira segundo Corazza et al. (2001) que é a utilização de albumina, ou seja, a clara de ovo na proporção de uma colher de sopa por litro de vinho, após a homogeneização da mistura, centrifugou-se durante 5 minutos realizando mais uma filtração.

A última etapa consistiu na pasteurização do vinho em banho-maria a $60^{\circ} \mathrm{C}$ por 40 minutos em um equipamento da TECNAL, modelo TE-054 mag específico para banho-maria, logo após o vinho foi resfriado naturalmente e engarrafado em litros de vidro de $750 \mathrm{ml}$, fechados com rolha para sua conservação.

\subsection{Parâmetros fermentativos}

Com base no monitoramento dos estudos cinéticos a produção de etanol foi observada durante 308h de fermentação na ausência e presença de casca. A partir dos resultados pode se verificar os rendimentos (conversão de substratos em produto), a eficiência e a produtividade da fermentação. Os parâmetros fermentativos são importantes no desenvolvimento das leveduras, pois determinam quais são as melhores condições de tratamento a ser desenvolvido, mantendo um produto economicamente viável e estabilizado para sua produção em larga escala.

\subsection{Caracterização físico-química}

O acompanhamento da fermentação foi por meio de análises físico-químicas. Durante o processo fermentativo foram retiradas amostras para caracterização do mosto, a partir de parâmetros como ${ }^{\circ}$ Brix, concentração de álcool e concentração de açúcar, segundo descrição a seguir.

- $\mathrm{pH}$ e temperatura: foi utilizado um pHmetro digital, em que os resultados eram dados ao mesmo tempo em que o eletrodo era mergulhado na amostra a ser analisada contida em béqueres de $100 \mathrm{ml}$.

- Teor de sólidos solúveis ( ${ }^{\circ}$ Brix): para a obtenção de sólidos solúveis foi utilizado um 
refratômetro portátil para açúcar.

- Turbidez: para medir a turbidez a amostra era colocada em mini tubos de ensaio de $40 \mathrm{ml}$ tampados com tampa de plástico preta para inibição da luz externa ao ambiente.

- Concentração de sacarose: a propriedade utilizada para o cálculo da concentração de sacarose foi o grau Brix, correlacionando-o linearmente com a concentração de açúcar conforme equação (1).

$$
C A=10,13 *\left({ }^{\circ} \text { Brix }\right)+1,445
$$

em que, CA é a concentração de açúcar dada em gramas por litros.

- Teor alcoólico: foram utilizados dados da variação nos valores de ${ }^{\circ}$ Brix no início da fermentação e ao final do processo, conforme equação (2).

$$
T A=\frac{\left({ }^{\circ} \text { Brix }_{\text {inicial }}-{ }^{\circ} \text { Brix }_{\text {final }}\right) \cdot 4}{7,4}
$$

em que, TA é o teor alcoólico dado em gramas por litro.

\section{RESULTADOS E DISCUSSÕES}

O processo foi realizado em condições variáveis ( $\mathrm{T}, \mathrm{pH}$, etc.), a fim de se observar, quantificar e comparar a influência da adição de levedura no mosto.

Com base no monitoramento do estudo cinético, a produção de etanol foi observada durante $308 \mathrm{~h}$ de fermentação na ausência e presença de casca. As Figuras 1 e 2 apresentam os resultados obtidos para teor alcoólico e a concentração de açúcar, em função do tempo de fermentação.

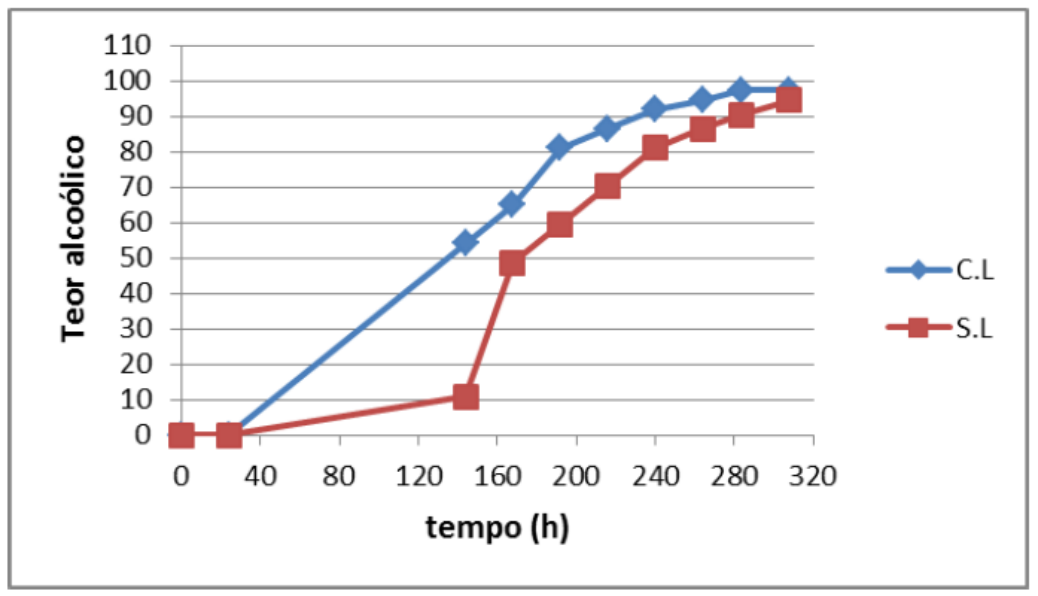

Figura 1 - Teor alcoólico durante a fermentação. C.L: com levedura; S.L: sem levedura. 


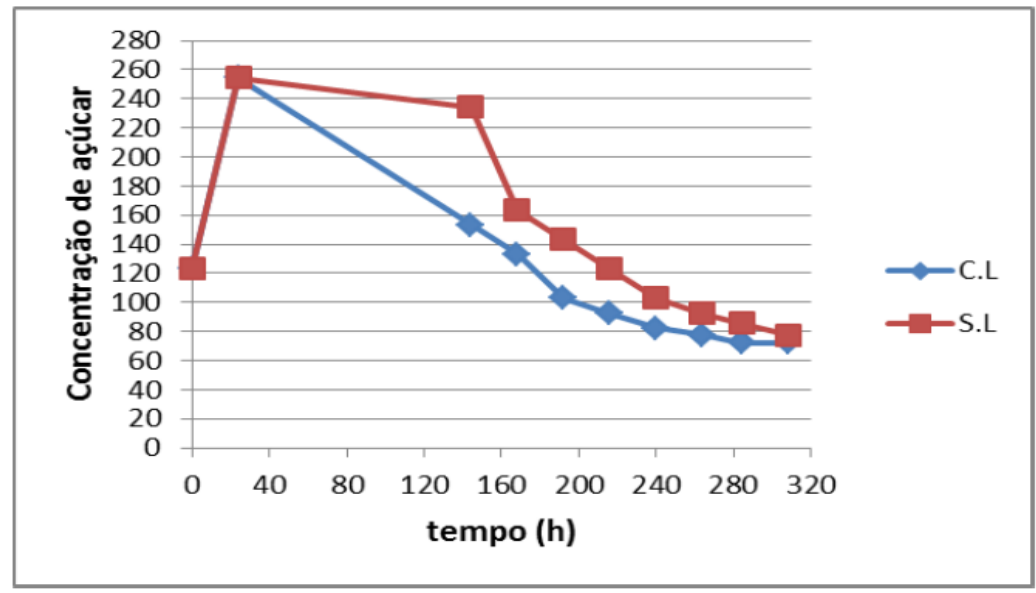

Figura 2 - Concentração de açúcar consumida durante a fermentação. C.L: com levedura; S.L: sem levedura.

A partir da análise dos vinhos, nas Figuras 1 e 2, verifica-se que a produção alcoólica obtida foi proporcional em ambos os casos analisados, principalmente para o valor final da graduação alcoólica. Durante as primeiras $144 \mathrm{~h}$ de fermentação com a levedura houve um disparo e produziu $5,4^{\circ} \mathrm{GL}$ o qual resultou em um fermentado de $76,86 \mathrm{~g} / \mathrm{L}$ de álcool por litro de vinho. No mosto sem adição de levedura houve um pequeno disparo em $144 \mathrm{~h}$ de fermentação produzindo $1,08{ }^{\circ} \mathrm{GL}$ e deu um avanço em 168 h com a produção de 4,8 GL mantendo constante o aumento até as 308 h que resultou em um fermentado de 72,74 g/L de álcool por litro de vinho. A adição de $600 \mathrm{~g}$ de açúcar e $20 \mathrm{~g}$ de levedura no mosto a ser fermentado proporcionou uma produção de álcool mais rápida e em menor tempo quando comparada com a fermentação espontânea, verificando-se que maiores teores de sólidos solúveis totais (SST) favorecem maior produção de etanol.

A partir dos resultados obtidos pode-se verificar o rendimento, a eficiência e produtividade da fermentação conforme Tabela 1.

Tabela 1 - Parâmetros fermentativos

\begin{tabular}{lcccccc}
\hline \multirow{2}{*}{ Parâmetros } & $\begin{array}{c}\text { Rendimento } \\
\left(\mathrm{g}_{\text {etanoo }} / \mathrm{g}_{\text {glicose }}\right)\end{array}$ & $\begin{array}{c}\text { Eficiência } \\
(\%)\end{array}$ & $\begin{array}{c}\text { Produtividade } \\
(\mathrm{g} / \mathrm{L} . \mathrm{h})\end{array}$ \\
\cline { 2 - 7 } & 1 & 2 & 1 & 2 & 1 & 2 \\
\hline Com levedura & 0,421 & 0,421 & 82,49 & 82,49 & 0,296 & 0,110 \\
Sem levedura & 0,421 & 0,421 & 82,49 & 82,49 & 0,059 & 0,215 \\
\hline 1- fermentação na presença de casca; 2 - fermentação na ausência de casca.
\end{tabular}

Os valores representados para o fator rendimento $\left(\mathrm{Y}_{\mathrm{p} / \mathrm{s}}\right)$ foi praticamente o mesmo com a presença ou não de casca no mosto em fermentação, apresentando valores de $0,421 \mathrm{~g}_{\text {etanol }} / \mathrm{g}_{\text {glicose }}$ com a adição de levedura e $0,4215 \mathrm{~g}_{\text {etanol }} / \mathrm{g}_{\mathrm{glicose}}$ na ausência desta. A eficiência corresponde a conversão de açucares totais presentes no meio e foi de $82,49 \%$ nos dois casos. Já para a produtividade houve uma pequena variação em relação à presença e ausência de casca no mosto, como também o fator adição de levedura, obtendo-se os seguintes resultados com levedura e casca 0,296 (g/L.h), e sem casca 


\section{9 a 22 de outubro de 2014 \\ Florianópolis/SC}

0,083 (g/L.h). Já para os casos sem levedura, foram de 0,059 (g/L.h) com casca e 0,118 (g/L.h) sem casca. Em termos de produtividade, verificou-se que a fermentação com adição de levedura, apresentou melhores resultados, tanto na presença quanto na ausência de casca durante a fermentação.

A Tabela 2 apresentada os resultados obtidos para a variação de temperatura, $\mathrm{pH}$, consumo de sólidos solúveis e turbidez, observados durante os 14 dias consecutivos de fermentação, sendo os cinco primeiros dias com casca e o restante dos dias sem a presença deste.

Tabela 2 - Variação das propriedades físico-químicas do mosto durante a fermentação

\begin{tabular}{ccccccccc}
\hline Tempo de fermentação & \multicolumn{3}{c}{$\mathrm{pH}$} & \multicolumn{3}{c}{ Brix } & \multicolumn{3}{c}{ Temperatura $\left({ }^{\circ} \mathrm{C}\right)$} & \multicolumn{2}{c}{ Turbidez (NTU) } \\
\cline { 2 - 9 }$(\mathrm{h})$ & $\mathrm{A}$ & $\mathrm{B}$ & $\mathrm{A}$ & $\mathrm{B}$ & $\mathrm{A}$ & $\mathrm{B}$ & $\mathrm{A}$ & $\mathrm{B}$ \\
\hline 24 & 3,35 & 3,25 & 12 & 12 & 0 & 0 & 0 & 0 \\
144 & 3,6 & 3,57 & 25 & 25 & 25 & 24,9 & 1146 & 1184 \\
168 & 3,65 & 3,6 & 13 & 16 & 30 & 25,9 & 1078 & 1070 \\
192 & 3,68 & 3,62 & 10 & 14 & 25,6 & 24,5 & 1169 & 1172 \\
216 & 3,72 & 3,66 & 9 & 12 & 32 & 29,5 & 934 & 1167 \\
140 & 3,73 & 3,7 & 8 & 10 & 25,9 & 27 & 1010 & 1158 \\
264 & 3,75 & 3,72 & 7,5 & 9 & 28,5 & 29 & 1026 & 1160 \\
284 & 3,77 & 3,75 & 7 & 8,3 & 29,5 & 30 & 998 & 1153 \\
308 & 3,78 & 3,75 & 7 & 7,5 & 33 & 32,5 & 968 & 1120 \\
\hline \multicolumn{1}{c}{ A - Com adição de levedura; B - Sem adição de levedura. }
\end{tabular}

Foi possível observar que durante a fermentação que o $\mathrm{pH}$ do meio não apresentou grande mudança mas sim um aumento que acabou estabilizando em 3,75 para ambas condições. Houve um decréscimo do ${ }^{\circ}$ Brix após a chaptalização durante as primeiras $216 \mathrm{~h}$ de fermentação caindo de $1,7^{\circ}$ Brix com levedura e $1,5^{\circ}$ Brix sem levedura. Após esse período, houve a estabilização de $7^{\circ}$ Brix com levedura e $7,5^{\circ}$ Brix sem levedura, correspondendo a produção de $9,72{ }^{\circ} \mathrm{GL}$ e $9,45^{\circ} \mathrm{GL}$ para o mosto com correção e sem adição de levedura, respectivamente. A temperatura não apresentou garne variação e manteve-se dentro satisfatório para o desenvolvimento da fermentação alcoólica, de 24 a $33^{\circ} \mathrm{C}$. A Turbidez mostrou um decaimento nas $216 \mathrm{~h}$ no mosto com adição levedura, apresentando um comportamento de fermentação tumultuosa do começo ao fim do processo, com a presença ou não de cascas.

O fermentado apresentado neste trabalho foi classificado como do tipo suave, cujo teor de açúcar esteve entre 72,35 e 77,42 g/l, classificado nesta categoria segundo a legislação brasileira (UVIBRA, 2009). O vinho produzido foi de cor de rosada, correspondendo ao tipo de uva utilizada no processo. O vinho produzido apresentou coloração roxa escura, que foi estabilizando até a cor final roxa, característica de vinhos tintos.

\section{CONCLUSÕES}

O presente trabalho apresentou um estudo da produção caseira de vinho de mesa a partir de uvas dos cultivares Rubi. Em relação ao rendimento e a eficiência do processo fermentativo, o produto formado durante a fermentação na ausência e presença de casca, com e sem a adição de levedura, apresentou resultados semelhantes. Em termos de produtividade, a fermentação com adição de 
levedura, apresentou melhores resultados, tanto na presença quanto na ausência de casca na fermentação.

O mosto fermentado espontaneamente, sem a ação da levedura, apresentou resultados de teor alcoólico de $9,45^{\circ} \mathrm{GL}$, rendimento em etanol de $0,421 \mathrm{~g}_{\text {etanol }} / \mathrm{g}_{\text {glicose }}$ e produtividade de $0,059 \mathrm{~g} / \mathrm{L} . \mathrm{h}$. No caso do mosto adicionado da S. cerevisiae, o vinho obtido tinha teor alcoólico de $9,73^{\circ} \mathrm{GL}$, rendimento em etanol de $0,42154 \mathrm{~g}_{\text {etanol }} / \mathrm{g}_{\text {glicose }}$ e produtividade de 0,296 $\mathrm{g} / \mathrm{L} . \mathrm{h}$. A eficiência da conversão dos açúcares totais foi de $82,49 \%$. Verificou-se, portanto, que a presença de levedura não alterou a eficiência do processo fermentativo. No entanto, uma pequena variação na produção de etanol foi verificada. Contudo os resultados obtidos foram praticamente os mesmos, tratando-se da presença ou ausência da casca no mosto fermentado.

De acordo com as caracterizações físico-químicas, o vinho obtido foi do tipo suave. Constatouse que o fermentado continha uma graduação alcoólica exigida pela legislação brasileira, o que foi possível classificá-lo como vinho de mesa. Atribui-se tal resultado a adição de açúcar ao mosto, independentemente da adição da levedura Saccharomyces cerevisiae.

\section{REFERÊNCIAS}

BRASIL. Lei $n^{\circ}$ 7.678, de 8 de novembro de 1988. Brasília, DF.

BORZANI, W. Fermentação alcoólica. Em: BORZANI, W.; SCHMIDELL. W.; LIMA, U. A.; AQUARONE, E. Fundamentos. São Paulo: Edgard Blücher, 2001.

CORAZZA, M. L.; RODRIGUES, D. G.; NOZAKI, J. Preparação e caracterização do vinho de laranja. Química Nova, v. 24, n. 4, p. 449-452, 2001.

HASHIZUME, T. Tecnologia do vinho. Em: AQUARONE, E.; BORZANI, W.; SCHMIDELL, W.; LIMA, U. A. Biotecnologia na Produção de Alimentos. São Paulo: Edgard Blücher, 2001.

HENSON, M. Teor alcoólico dos vinhos. 2012. Disponível em:<http://ememoo.blogspot.com.br/2012/10/teor-alcoolico-dos-vinhos.html>. Acesso em: 29 mar. 2014.

LIMA, U. A.; BASSO, L. C.; AMORIM, H. V. Produção de etanol. Em: LIMA, U. A.; AQUARONE, E.; BORZANI, W.; SCHMIDELL, W. Processos fermentativos e enzimáticos. São Paulo: Edgard Blücher, 2001.

NACHTIGAL, J. C.; CAMARGO, U. A. Sistema de produção de uva de mesa no norte do Paraná: cultivares. Em: Embraba Uva e Vinho: Sistema de Produção [online], ISSN 1678-8761, dez. 2005. Disponível em: < http://www.cnpuv.embrapa.br/publica/sprod/MesaNorteParana/cultivares.htm>. Acesso em: 14 de mar. 2014.

UNIÃO BRASILEIRA DE VITIVINICULTURA (UVIBRA). Portaria $n^{\circ} 229$, de 25 de outubro de 1988. 2009. Disponível em: <http://www.uvibra.com.br/legislação_portaria229.htm>. Acesso em: 26 mar. 2014.

TORTORA, G. J.; FUNKE, B. R.; CASE, C. Microbiologia. Porto Alegre: Artmed, 2005. 
19 a 22 de outubro de 2014

Florianópolis/SC

WINE. Luis Duarte: um dos melhores enólogos do mundo do vinho. Sommelier wine [online].

Disponível em:<http://www.sommelierwine.com.br/2012/09/26/luis-duarte/>. Acesso em: 26 mar. 2014. 